\title{
Teaching Practice and Exploration about Motor and Drive Course Based on Integration of "Teaching, Learning and Doing"
}

\author{
Weimin Chen ${ }^{1, a}$, Hui Cai ${ }^{1, a}$, Guanqun Sun ${ }^{1, a}$ and Nan Xie ${ }^{2, b^{*}}$ \\ ${ }^{1}$ College of Mechanical and Electrical Engineering, China Jiliang University, Hangzhou, China \\ ${ }^{2}$ Information Engineering and Art \& Design College, Zhejiang University of Water Resources and \\ Electric Power, Hangzhou 310018, China. \\ acwm@cjlu.edu.cn, ${ }^{\mathrm{b}} 595075251 @ q q . c o m$ \\ The corresponding author
}

\begin{abstract}
Keywords: Motor and drive; Teaching; Learning and doing; Scene simulation; Task driven; Teaching practice
\end{abstract}

\begin{abstract}
Motor and Drive is one of professional basic courses about electrical engineering and automation specialty, and it has strong theoretical and practical characteristics. For undergraduate colleges and universities, it is important for students to grasp the theoretical knowledge, but also students can take practical application as a starting point to solve some specific problems. The Course teaching team members have improved the traditional teaching method. With the integration of "teaching, learning and doing", they have put forward a variety of teaching methods, which having been used into the course teaching practice in order to achieve the "learning to do, to do secondary school" teaching goal. After two cycles of instruction practice, the teaching effect of "teaching" and "learning" in the course has improved significantly.
\end{abstract}

\section{Introduction}

Motor and Drive course is the main course of electrical automation, mechanical and electrical engineering professional and it is one of the important fundamental courses. The course's theory and practice requirements are very high, and its knowledge includes electric, magnetic, electrical and mechanical, the basic concept and basic theory knowledge, interaction complex relationship. Mastering this course needs a lot of theoretical study time, and the abstract theoretical knowledge enable students to practice and previous teaching process exists more contents and less lessons. [1-3] In addition, students have great fear on the course of studying. In order to help students overcome the fear, stimulate students interest in learning, how to let the students master the basic theory and solve the practical engineering problems, the course of the teaching team have done some teaching practice and the corresponding teaching discussion.

\section{Curriculum Teaching Implementation Plan Design}

In modern industry, motor load and motor control, is widely used. In the course of the currently widely used in the motor and electric drive as the focus, through the project modularization theory of classroom teaching, situational simulation of network teaching and task driven teaching practice law three parts for teaching [4,9-10]. Theory teaching in the course of courseware animation to explain the course, the detailed analysis of the working principle of the motor, design concept, work characteristics and the application of ideas. Network teaching through the scene simulation teaching method, through the network course teaching video and my school network courseware platform was established based on the blackboard platform course website, through the network platform to promote students' extracurricular learning. The usefulness of the practice teaching highlights curriculum is divided into two parts: laboratory physical experiment and practice, mainly to three tasks of experiment teaching as the main task driven teaching method, and use scenario simulation method and project teaching to carry on the simulation and the teaching practice, through the practice 
of teaching improve students application ability of the motor. The specific curriculum teaching plan has been shown as Fig. 1.

\section{Curriculum Teaching Implementation}

Classroom Theory Teaching. This course is theoretical, abstract concepts and professional characteristics significantly, it is the professional from the theoretical basis, technical theory to the professional course study and engineering application study based and link, the system master theoretical knowledge of this course is to achieve the necessary condition of the electric drive control. In existing limited hours under, in order to improve the students' learning interest and passion, the teaching team members for the curriculum tailored 13 animation teaching courseware, boring theory become more dynamic and specific, focuses on the basic principles of motor and open-loop electric drive principle, guide the students to understand the motor electric current, the magnetic field and electromagnetic torque of causality, motor operating characteristics analysis, to enable students to master the important principle of separately excited motor electromagnetic principle, the structure of the motor and the motor operating characteristics of motor and drag, from "teaching" and "learning" in inspiration, a "to do" to lay the foundation [5-6]. And the application, using and commutation of the motor will be explained through the network teaching.

Scenario Simulation Network Teaching. Network teaching is to make up for this course, an important means of classroom teaching hours less, the course of the students open network teaching platform based on blackboard, the teaching platform are: multimedia courseware, teaching video, network resources, teaching practice, operation test, topic discussion, exchange and Q \&amp; A, course construction and teaching information module. Network course teaching video and multimedia courseware contains both the content in classroom teaching has been also contains the class is limited in the classroom did not speak and other content, through this module students both to consolidate have learned theoretical knowledge and expansion to other aspects of motor cognition. He gradually familiar with each motor principle, operating characteristics and the principle of motor is used to solve some practical problems in simple network video courses mainly in situational teaching method, electric motor and driving principle, the running characteristic and application integration of analysis and integration, students can also achieve the feeling of be personally on the scene.

Network resource module contains a motor factory for manufacturing some of the videos, well-known experts and motor cutting-edge videos of lectures and the current popular motor related forums [7-9]. This module can help students' perceptual knowledge of the motor structure, deepening the knowledge and understanding of motor development and motor application. Topic discussion, communication and question and answer module provides an interactive platform, which is an important means to promote students' Extracurricular Autonomous Reading, network interactive teaching process as shown in Fig. 2. Such as DC motor teaching about DC motor reversing existing problems and improvement methods, classroom teaching only in the motor structure about mentioned, but not detailing, network teaching teachers mainly proposed the question and literature references are given, each student is required to analyze the problem and puts forward the corresponding improvement measures, and can play to the imagination. For such a problem, students have a certain theoretical basis, should be able to solve the problem by consulting the literature. This network can not only save the time of classroom teaching, but also encourage students to study outside class. Teachers can also discuss the situation of students' extracurricular learning through subject discussion.

Job network is a supplement to the network teaching, network operations are different from the classroom arrangement homework book, decorate the classroom books work the aim is to grasp the theory knowledge, and network operation is mainly to expand students' technical application. Such as for DC motor network operations: 1) a given load conditions and asked to select the appropriate motor. These motors must be online can buy products; 2) if you want of an electric drive system for speed, please control design scheme, draw speed control principle diagram, list the equipment list of 
expenses. Through these networks can enable the students to fully practice, to solve practical problems, but also can stimulate their interest. The test is a way to test students' learning situation, also make some preparations for the exam.

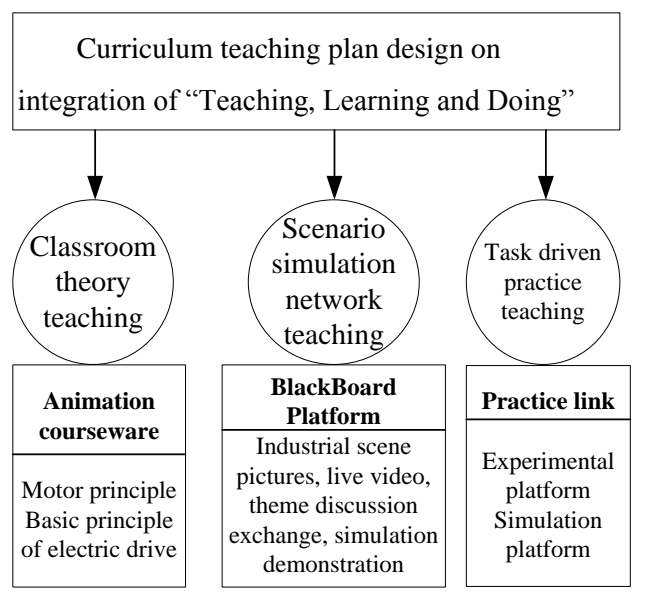

Figure 1. Curriculum teaching plan design

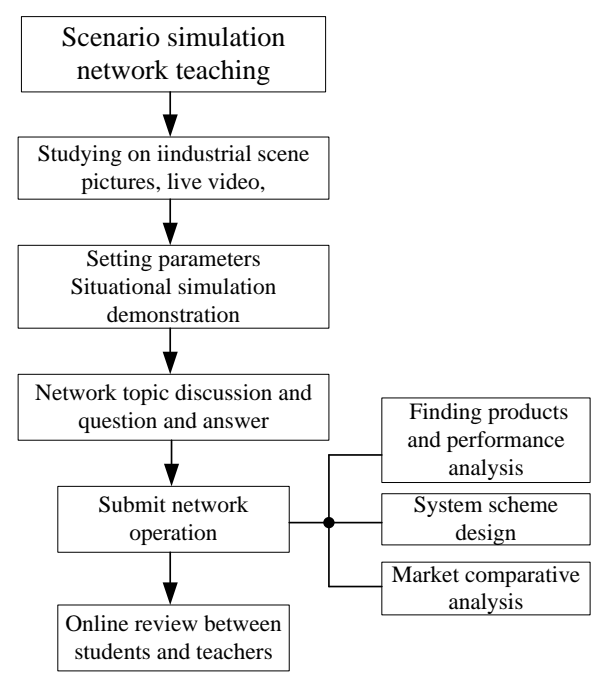

Figure 2. Network teaching process

Practice Teaching. Practice is an important means to improve students' occupation skill; no practice is always empty talk. Taking into account of the experimental class and the condition of experiment and practice teaching of this course is divided into laboratory physical practice and MATLAB / Simulink simulation teaching, give students set 3, 4 and 5 teaching task, the task driven method in teaching practice.

Physical experiment teaching has two parts: experiments required and elective experiment [5-7]. Experiments required a motor winding, DC motor operating characteristics, three-phase induction motor operating characteristics, elective experimental DC generator operating characteristics, DC series excited motor operating characteristics, single-phase and three-phase transformer, three-phase motor start and speed control, operation of single-phase AC motor, synchronous motor, and so on. The experiment has experimental guide video, if the students do experiment by elective laboratory reservation, and then through the experimental guidance of video learning on the network platform to the laboratory.

Motor Simulink simulation experiment based on MATLAB is an important method to improve students' motor. This course compiling simulation experimental guide books, the content is divided into three parts: the electrical part of the introduction of Simulink, the simulation of DC motor and AC motor simulation. Simulation of DC motor: the mechanical characteristics of DC motor starting, braking and speed regulation simulation example; AC motor starting, speed and other examples. The students in extracurricular simulation in accordance with the routine, and results of simulation files uploaded to the network platform, finally independent and complete an integrated experiment. For example, when a student learning of motor starting, braking and speed regulating theory, comprehensive experiment for a enable asynchronous motor can realize positive rotation, reverse rotation and motion function of electric drive control system, through the simulation design scheme of the correctness of the design.

\section{Course Assessment Methods}

Because the course of Situational Method network teaching is to make up for the current teaching class of important means and an important link of teaching, through the approach to the assessment of the promote students learning motivation and through extracurricular electric drive based simulation application can improve the application ability of the students. Therefore, this course will assess is 
divided into four parts, respectively course test papers (60\%), the discussion network quality evaluation (10\%), online discussions and submit homework quality (15\%), as well as experimental evaluation (15\%), this evaluation set can fully mobilize students' learning autonomy [9].

After the implementation of the teaching of two cycles of instruction, the author from two aspects of students and experts from campus to the teaching effect were evaluated mainly reflected in students interested to review knowledge and products of motor learning, willing to learn, also want to do! The positive attitude of the study also greatly improved, before the students are afraid of the exam, in order to test and study, and now become active learning and hands-on practice, to "teach, learn, do" one good teaching effect. In addition, through the school expert lectures also give a good evaluation of this course, teaching methods, teaching atmosphere is not boring, more active.

\section{Conclusion}

In this paper, the new curriculum theory of complex, less teaching hours, the traditional classroom teaching and network teaching combined with the scenario simulation method, driven by the project task oriented and online video teaching a variety of teaching methods, to enable students to passive learning into active, maximize inspire students' potential, do "teaching, learning, doing" one, really let the students "learning to do, learning by doing" teaching effect is achieved. Course, proceeding from the actual conditions, provide students with hands-on practice to solve practical problems of ideas and methods, give students create better learning platform and more independent thinking space, to create a good learning atmosphere, and improve the teaching quality of this course.

\section{Acknowledgements}

This work was supported by Zhejiang Key Discipline of Instrument Science \& Technology.

\section{References}

[1]. Zhang Yanxia, Zhang Jingjie. Implementation and Promotion on Integration of theory and practice teaching mode in Motor and Drive course [J]. Zhengzhou University of Aeronautics (Social Science Edition), 2016(4): pp. 201-204

[2]. Yang Yong. Research on the overall design of the motor and drag foundation course based on project teaching [J]. Education Teaching Forum, 2014 (30): pp. 233-234,175

[3]. Zhong Guoliang, Lu Fanxing, Li Minghui. The teaching reform and practice of the core course of motor and drag foundation [J]. China Electric Power Education, 2013 (13): pp. 63-64

[4]. Bao Xiaohua, Wang Yao, Hua Yuting, Ni Youyuan et al. Innovative teaching and exploration in the practice of teaching reform of Motor and Drive course [J]. China Electric Power Education, 2011 (12): pp. 166-167.

[5]. Wang Xuhong, Ouyang Ming. The reform and innovation of experimental teaching of Motor and Drive course [J]. China Electric Power Education, China Machine Press, 2012 (23): pp. 75-76.

[6]. Liu Huijuan, Zhang Wei. Research on the teaching of virtual experiment of Motor and Drive course [J]. China Electric Power Education.2008 (21): pp. 147-148.

[7]. Zhang Yuping. Teaching reform and practice of the course of Motor and Drive [J]. Journal of Shijiazhuang Institute of Railway Technology, 2012.12: pp. 98-101.

[8]. Sun Guanqun, Cai Hui, Li Jing, Li Mei. Research on the teaching reform of electrical engineering courses in the application oriented undergraduate course $[\mathrm{J}]$. China Electric Power Education, 2011 (21): pp. 176-177.

[9]. Motor and Drive course Learning Site based BlackBoard. HTTP://JWC.CJLU.EDU.CN 
[10]. Excellent Course Learning Web of Chang ${ }^{6}$ an University. HTTP://JPKC.CHD.EDU.CN/DJJTDJC/ 